\section{Uma 'biblioteca sem paredes': história da criação da Bireme*}

\section{A 'library without walls': a history of the creation of Bireme}

Márcia Regina Barros da Silva Pesquisadora do Centro de História e Filosofia das Ciências da Saúde - Unifesp Rua Tiro ao Pombo, 402/94 bloco 31 02844-060 São Paulo - SP - Brasil mbarros.cehfi@epm.br

Luis Ferla

Professor de Pós-Graduação - FAAP Rua Girassol, 922, ap. 102-A 05433-002 São Paulo - SP - Brasil

luis.ferla@terra.com.br

Dante Marcello Claramonte Gallian

Docente e Diretor do Centro de História e Filosofia das Ciências da Saúde - Unifesp

Rua Botucatu, 740 - Museu Histórico 04023-900 São Paulo - SP - Brasil dante.cehfi@epm.br
SILVA, M. R. B. da; FERLA, L.; GALLIAN, D. M. C. Uma 'biblioteca sem paredes': história da criação da Bireme.

História, Ciências, Saúde - Manguinhos, v. 13, n. 1, p. 91-112, jan.-mar. 2006.

O presente artigo analisa o processo de criação da Bireme, Centro Latino-Americano e do Caribe de Informação em Ciências da Saúde, relacionando-o com o contextos social, político e econômico respectivos. O período em questão assistiu à solidificação da influência norte-americana no mundo ocidental, entre as décadas de 1950 e 1970. Nossa intenção foi resgatar documentos e depoimentos referenciais para discutir as questões envolvidas na implantação da então Biblioteca Regional de Medicina, iniciativa que teve grande influência no âmbito da integração cultural e científica latinoamericana no campo das ciências da saúde. Procurou-se ainda estabelecer marcos analíticos que possibilitem reflexões sobre o desenvolvimento histórico da instituição e sobre seu papel como iniciativa da Organização Panamericana de Saúde.

PALAVRAS-CHAVE: Bireme; biblioteca; história; ciências da informação; América Latina; ciências da saúde.

SILVA, M. R. B. da; FERLA, L.; GALLIAN, D. M. C.: A 'library without walls': a history of the creation of Bireme

História, Ciências, Saúde - Manguinhos, v. 13, n. 1, p. 91-112, Jan.-Mar. 2006.

Approaching from the framework of social, political, and economic contexts, the article analyzes the process involved in creation of the Latin American and Caribbean Center on Health Sciences Information (Bireme). The period in question coincides with the consolidation of US influence in the West, between the 1950s and 1970s. A recovery and examination of reference documents and testimonies permits a discussion of the issues involved in setting up what was first known as the Regional Library of Medicine, an initiative in cultural and scientific integration that was highly influential in Latin American health sciences. The article offers reflections on the historical development of the institution as an initiative of the Pan American Health Organization and its subsequent role.

KEYWORDS: Bireme; library; history; information sciences; Latin America; health sciences. 


\section{O papel da OPAS na condução das propostas para a saúde na América Latina}

Dassados 35 anos, analisar a criação da Bireme pode ser um exercício duplamente significativo, uma vez que permite compreender parte da história da saúde e da educação médica no Brasil e também parte dos processos de consolidação e expansão da própria Organização Panamericana de Saúde - OPAS, que completou recentemente cem anos de atuação na América Latina. Nossa intenção é levantar questões que possam indicar as diretrizes envolvidas nos processos de planejamento e inauguração da Bireme, relacionados a alguns aspectos das transformações por que passava o ensino médico no período.

A Biblioteca Regional de Medicina, conhecida como Bireme, foi fundada em 3 de março de 1967, através de convênio firmado entre a OPAS, os Ministérios da Educação e Cultura e da Saúde do Brasil e a Escola Paulista de Medicina - EPM.Apesar de ser um acordo conjunto entre diferentes entidades, o destaque maior na condução do projeto e do planejamento da Biblioteca coube à própria OPAS, em concordância com as diretrizes de trabalho que a agência passou a assumir no período posterior à Segunda Guerra Mundial.

A influência dessa agência e dos auxílios posteriores de outras fundações como Fundação Milbank e Rockefeller na consecução de um novo modelo de biblioteca médica participava das propostas e estratégias de reorientação da formação de recursos humanos em saúde e de adequação do ensino médico empreendidas nos anos 70 por toda a América Latina.

No que se relaciona à saúde, a América Latina em geral saía de um ciclo de propostas de erradicação de enfermidades, com alguns êxitos a partir já do início do século XX. A década de 1940 definiu um marco nesse processo, na medida em que significou uma considerável redução na incidência das doenças epidêmicas, especialmente da tríade ancilostomíase, febre amarela e malária. Essa constituiu mais uma expressão do processo de consolidação da medicina norte-americana, que se instalava como centro de influência científica e técnica no mundo. As mudanças decorrentes da Segunda Guerra Mundial, e suas conseqüências no âmbito do pensamento, da cultura e da tecnologia (Hobsbawm, 1995; Sevcenko, 2001), influenciaram fortemente o universo das ciências da saúde, repercutindo principalmente no campo das políticas sanitárias (Cueto, 1996).

Em 1946, como parte daquela influência, havia sido criada a Organização Mundial de Saúde-OMS, agência oficial da Organização das Nações Unidas, responsável pela coordenação internacional das ações referentes a saúde (Lima, 2002). Porém, na década de 1950, mesmo com a grande diminuição das doenças epidêmicas, algumas 
delas ainda se faziam sentir, tanto nos centros desenvolvidos como os Estados Unidos, onde a poliomielite registrava $20 \mathrm{mil}$ casos ao ano (cf. PAHO, 2002) - quanto nos países periféricos como o Brasil, onde a malária aparecia sob a forma endêmica em "mais de 84\% do território" (Finkelman, 2002, p. 179).

As referências à soberania e à ampliação da zona de influência norte americana nas questões da saúde se multiplicavam. Envolviam desde propostas de auxílios, inauguradas com o presidente Truman, em 1949, visando à transferência de partes de conhecimentos científicos e industriais para áreas subdesenvolvidas, passando pelos projetos de erradicação da malária com DDT após os anos 50, indo até os processos de ordenamento estratégico de políticas de segurança nacional, sob a proposta americana denominada Aliança para o Progresso. Desde então não restam dúvidas sobre a utilização estratégica da saúde, tanto para as perspectivas desenvolvimentistas daquele período, quanto para a propagação de uma hegemonia norte-americana na América Latina.

Sediada em Washington (DC), a OPAS concorreu para o processo de modernização pelo qual passava a América Latina, patrocinando a discussão e a elaboração de políticas, projetos e planos de ação voltados para a promoção da saúde coletiva nos países da região. No interior desse processo, as questões de educação e de divulgação da informação científica e da formação de recursos huma-nos participavam do ideário sustentado pelas questões mais clássicas, referentes à inserção dos países latinos nos temas da industrialização 'periférica', da expansão do trabalho assalariado e dos mercados internos, bem como do papel do Estado como promotor do desenvolvimento.

O projeto científico para a saúde apoiado pela OPAS não buscava apenas promover a pesquisa científica. Apoiava, também, a busca de crescentes recursos tecnológicos, com o fim de fomentar a difusão e a disseminação da informação científica, investindo, portanto, num tipo de educação e conhecimento médico que teve como efeito políticas de expansão do ensino médico e de construção de um sistema de pós-graduação na área para os países latino-americanos.

Segundo Juan Garcia, se nos anos 50 as proposições no campo da saúde sustentavam-se sobre o conceito de controle das doenças, nos anos 70 a sistemática seria a teoria de sistemas e de serviços de informação como meio de 'vigiar' o sistema de saúde, e a universidade aparecia como um lugar possível para a construção desse processo (Garcia, 1972, p. 212, in Duarte, 1989).

Alguns dados prévios apontam para a formação de uma unidade em torno desses novos procedimentos que caracterizaram as relações entre saúde, educação médica e as inovações relacionadas a essas áreas ao longo dos anos 70. Nas disposições da XV Reunião do Conselho Diretivo da OPAS, realizada em 1964, vemos um bom 
exemplo do direcionamento que passava a vigorar nas atividades dirigidas pela agência:

3. Recomendar que la Organización preste el máximo de asesoramiento y colaboración para el desarrollo en los respectivos países de la investigación de salud pública, como apoyo imprescindible a las acciones sanitarias que desarrollan.

4. Recomendar a los Gobiernos que hagan todo lo posible por mejorar las instituciones de adiestramiento e investigación, a fin de desarrollar los recursos humanos en salud y las actividades de investigación, y prestar el máximo apoyo financiero y de otra índole para asegurar la necesaria cooperación y coordinación en las escalas nacional e internacional (Documento n. 60, 1965, p. 185-6).

A produção de conhecimento em questões de saúde nos países sob influência da OPAS passava, cada vez mais, a ser estimulada. Alguns passos específicos haviam sido dados neste sentido em momentos anteriores, principalmente com a realização de encontros de educadores médicos para reflexão sobre os interesses conjuntos no desenvolvimento da educação médica nas Américas, aliada à criação de novos espaços de avaliação cujo enfoque era especificamente a temática da pedagogia utilizada no ensino.

Um desses novos fóruns de discussão começou a surgir em 1951, quando se organizou o I Congresso de Educadores Médicos, em Lima, Peru. O evento contou com a participação de uma comissão conjunta da OPAS que analisou questões referentes a deficiências qualitativas e quantitativas do ensino médico em geral. $O$ fato de a OPAS haver sido reconhecida formalmente como organismo especializado na saúde do sistema das Américas em 1950 está contido no mesmo movimento de volta ativa das relações dos Estados Unidos com os países latino-americanos e com o direcionamento mais forte da Fundação Rockefeller a atividades relacionadas ao ensino médico (Garcia, in Nunes, 1989).

Uma iniciativa bastante abordada pela historiografia foi o patrocínio, em 1955 e 1956, dos Seminários sobre o Ensino da Medicina Preventiva e Social, respectivamente no Chile e no México. A intenção desses encontros era fortalecer a visão da medicina preventiva nos cursos de graduação em medicina, para alterar de algum modo o panorama da morbidade e da qualidade de vida dos países latino-americanos. Essas propostas tiveram como conseqüência mais visível a adoção de uma política de base 'preventivista', amplamente divulgada e incentivada pela OPAS até o começo dos anos 70 (Nunes, 1999-2000).

Esse objetivo foi ampliado para destacar projetos que procuravam incentivar a reordenação do ensino de medicina, de modo geral, no sentido de apoiar a titulação acadêmica, a formação de 
docentes e o suprimento dos quadros universitários dos países envolvidos. Isto ocorria concomitantemente ao primeiro grande boom do ensino superior na América Latina. Em 1960, a taxa de crescimento anual médio do setor havia sido de 9,5 por cento, significativamente maior que os também altos 6,5 por cento do nível secundário; 3,6 por cento do primário; 5,4 por cento do pré-escolar, e 4,5 por cento da educação considerada globalmente ( $A$ explosão educativa, 1979, p. 38). A educação médica não constituiu exceção, incluindo a latino-americana e a brasileira, com altas taxas de crescimento no número de escolas de medicina e no número de matriculados, acompanhando o princípio da expansão da Big Science após a Segunda Guerra Mundial (Galison \& Hevly, 1992).

Diferentes projetos e estudos foram encaminhados pela OPAS para analisar a situação do ensino médico em diferentes países latinoamericanos nos anos subseqüentes aos dos seminários citados. A esses projetos foram associadas também discussões em torno das condições das bibliotecas médicas atreladas a cada escola, além de propostas de disponibilização de livros-textos para os estudantes, condizentes com os projetos de cada país.

Em 1965, por exemplo, verificava-se uma indicação direta de tal proposta no informe do diretor da entidade, Abraham Horwitz, na abertura da XVI Reunión del Consejo Directivo de la OPS e da XVII Reunión del Comité Regional de la OMS para las Américas, realizadas em setembro e outubro de 1965 (Documento n. 69, 1965).

Na sua apresentação, Horwitz, que foi diretor entre 1959 e 1975, apontava a proposta da $18^{\mathrm{a}}$ Assembléia Mundial da Saúde (ibidem, p. 37) de se estudar a situação das bibliotecas médicas, em virtude da grande participação de questões relacionadas ao ensino nos trabalhos da OPAS. Segundo ele, o interesse pelo ensino descenderia dos programas de adestramento de recursos humanos e serviços similares em toda a existência pregressa da instituição.

No entanto, essa era uma diretriz nova no projeto da instituição. No começo da década de 1960, os países membros da Organização dos Estados Americanos - OEA haviam firmado um compromisso de investir na adoção de recursos tecnológicos para a elevação do nível de vida das populações, na chamada Ata de Bogotá. Foi nesse contexto que, em 1961, como resultado da Reunião Extraordinária do Conselho Inter-americano Econômico e Social, criou-se o Plano Decenal de Saúde Pública e de Aliança para o Progresso, que assumiu definitivamente a idéia de desenvolvimento econômico e social como responsável pela promoção da saúde.

Por um lado, a hegemonia norte-americana já indicada se refletia significativamente também no campo das ciências e da medicina, deslocando definitivamente a influência européia para um plano secundário. Por outro, a guerra fria definiu uma radical bipola- 
rização do mundo, com as respectivas áreas de influência sendo objeto de políticas de intervenção sistemática das duas grandes potências. A Revolução Cubana, de 1959, dramatizou o confronto ideológico na América Latina, impulsionando os Estados Unidos a aprofundar a defesa de seus interesses na região. Isso, evidentemente, incluía uma presença mais cotidiana e capilar na execução de políticas sociais e econômicas. A Aliança para o Progresso e, em um nível diferenciado, a própria OPAS ganharam importância estra-tégica no trato com o tema da saúde.

Todos esses procedimentos que acentuavam o confronto ideológico e tentativas para predispor os países latino-americanos à influência americana, à incorporação de referenciais teórico-metodológicos específicos e unificados no que concernia à saúde, e conseqüentemente às exigências econômicas e institucionais do período, podem ser medidos nas palavras do então diretor da OPAS, Abraham Horwitz, sobre aquele momento:

La salud contribuye directamente al desarrollo económico y social, ya que prolonga la vida y aumenta la productividad, o indirectamente, puesto que facilita el aprovechamiento de los recursos naturales reduciendo o eliminando factores ambientales desfavorables. (in OPS, 1992, p. 59)

Em consonância com essa preocupação acerca do tema do ensino médico realizou-se, na mesma época, um trabalho de pesquisa que resultou na publicação de Juan César Garcia, intitulado La educación médica en la América Latina, publicado pela OPAS em 1972. No prefacio desse livro, Abraham Horwitz resumia a proposta da OPAS de atrelar as questões do ensino com uma ação integrada de resolução dos problemas de saúde na América Latina, fazendo a ligação entre medicina preventiva, educação médica e formação universitária:

Se fundaba en el propósito de permear el currículo de las ideas y métodos de prevención de las enfermedades y fomento de la salud. $\mathrm{Al}$ establecerse como un proceso, desde ingreso de los estudiantes a la Universidad, debería producir un nuevo modo de pensar, una actitud, que le permitiría al futuro profesional comprender el origen y la dinámica de la patología individual y social, determinando, en consecuencia, las medidas de prevención y curación correspondientes ... (Horwitz in Garcia, 1972, p. i).

Sua conclusão ia ao encontro da idéia de se dotar estudantes, os futuros médicos e profissionais da área, de condições para a busca de autonomia em solucionar as questões diversas que se colocassem durante o desempenho de suas funções: 
Se acepta hoy que el estudiante no debe ser sólo el objeto del proceso de enseñanza sino el sujeto del mismo, vale decir, un activo participante en todas sus fases, dado que se espera que él devuelva al medio social en servicios lo que la Institución y el país le entregaron. (Ibidem, p. ii)

Esse projeto, em conjunto com as demandas das explosões científica e tecnológica, está no cerne do ambiente de criação da Bireme. Primeiramente, enquanto instrumento de viabilização do fluxo crescente de informações na área; em segundo lugar, como ponto de contato entre a produção norte-americana e européia em medicina e os médicos e cientistas latino-americanos; e, em terceiro lugar, como perspectiva de um novo perfil para a gestão do conhecimento na área da saúde nos próprios países participantes do projeto e conseqüentemente para o possível funcionamento das bibliotecas latino-americanas de forma coordenada.

Ao discutir a construção dos Estados Nacionais latino-americanos, Sonia Fleury avalia que os princípios de 'modernização' e das estratégias de "incremento da intervenção estatal no mercado, com o desenvolvimento do direito social e da institucionalização de políticas sociais específicas" (Fleury, 1997, p. 135), tinham como fim apresentar políticas sociais e de cidadania que humanizassem o capitalismo na América Latina. O pano de fundo apontado para a consecução desse processo era o da crença no desenvolvimento progressivo das forças produtivas, assim como na incorporação de grupos, até então não absorvidos pelas respectivas sociedades. Nesse sentido o acento na idéia de circulação de conhecimento médico entre os centros mais desenvolvidos e os países da América Latina, que se coloca na proposta de construção de uma biblioteca, corresponderia a um auxílio para tornar a produção em saúde um dado para o desenvolvimento do bloco americano.

\section{Educação médica e intercâmbio científico}

No intuito de incentivar as atividades de aperfeiçoamento em educação médica, foi criada em 29 de novembro de 1962 a Federação Pan-americana de Associações de Faculdades (Escolas) de Medicina, sob a sigla Fepafem. ${ }^{1}$ A idéia de criação de tal entidade originara-se na já citada Terceira Conferência Latino-americana de Faculdades de Medicina, realizada no Chile, naquele mesmo ano.

Em 1964, de 16 a 22 de agosto, ocorreu a IV Conferência Latinoamericana de Faculdades de Medicina, em Poços de Caldas, no Brasil, promovida pela Fepafem e pela OPAS. Nessa reunião a idéia mais acabada de criação de uma biblioteca regional foi exposta. Samuel Lazerow, da National Library of Medicine (NML), dos Estados Unidos, apontava dados que justificariam a criação de um centro regional. 
Houve uma coincidência, não fortuita, de avaliação dos representantes presentes na reunião sobre o grande movimento no intercâmbio de artigos científicos entre a NLM e diversas bibliotecas latino-americanas. Horwitz assinalou tal questão, a partir da proposta da NLM para solucionar o problema de fluxo de informações daquela biblioteca, pois "más de la mitad del total de peticiones de información bibliográfica que recibe la Biblioteca Nacional de Medicina de los Estados Unidos de América - que cuenta com el mayor número de publicaciones del mundo - procede de América Latina" (Documento n. 69, 1965, p. 157).

No debate que se estabeleceu por meio da Oficina de Coordenação de Investigações e de seu coordenador, Raymond B. Allen, é possível perceber a afinidade nas preocupações da NLM e da OPAS. Esses pontos colocavam lado a lado a idéia de educação médica e de desenvolvimento regional. A marca desses processos consistiria em alinhar o trabalho médico e o trabalho científico, determinando as esferas sócio-econômicas e a reprodutibilidade do sistema:

Señala que se está preparando una propuesta de importantes programas para los Centros Regionales - para llevarse a cabo a plazo largo, que se mediría en decenios - que comprenderían actividades docentes y cursos sobre investigación a los problemas de estudios y el adiestramiento en los campos de la ingeniería biomédica, biosocial y biosanitaria. Como complemento a la política propuesta de apoyar el desarrollo de recursos institucionales para la enseñanza y la investigación, se encuentra la recomendación de establecer una Biblioteca Regional de Medicina para América Latina para fines de bibliografía y consulta, el desarrollo de investigaciones y adiestramento en biblioteconomía y en las ciencias de la comunicación. Aunque la América Latina está al día en cuanto a la tecnología y a la ciencia médica internacional, es necesario robustecer sus recursos para que tenga una actividad sostenida por sí misma. (Documento n. 69, 1965, p. 151)

Como órgão criado para organizar, ou pelo menos tentar unificar as instituições de ensino médico, a Fepafem foi reconhecida pela OPAS, que se comprometeu com o seu financiamento através da Resolução XV da 52a Reunião conjunta do Comitê Executivo da OPAS, em abril de 1965 (Documento n. 62, 1965, p. 15-6). Essa associação seria no mesmo momento indicada para patrocinar, juntamente com a OPAS, o funcionamento da Biblioteca Regional de Medicina (Documento n. 69, 1965, p. 404).

O fim imediato de tal centro regional seria o incentivo da produção de conhecimento local, com capacitação tecnológica e produção científica dos países latino-americanos, ao mesmo tempo em que seria incentivado um programa mais amplo de modernização 
institucional de bibliotecas, em que se incluía a NML (Documento n. 69 , p. 150-2).

Esse movimento de ordenação da produção científica, controle e institucionalização das estruturas educacionais era uma preocupação que foi sendo constituída desde anos anteriores, como uma intenção dos organismos oficiais em conhecer a produção latinoamericana e fomentar os acervos de cada país. Outra instituição oficial, a OEA, havia lançado em 1963 o primeiro Guia de Bibliotecas de La America Latina, produzido em conjunto com a Columbus Memorial Library, com o fim de produzir uma 'visão geral' sobre os dados existentes nas diferentes bibliotecas nacionais da região (OEA, 1963).

Retornando ao projeto da Biblioteca Regional, em abril de 1965, Mortimer Taube e David Kronick, dois bibliotecários norte-americanos, foram contratados como consultores pela OPAS para escolherem o país que poderia tornar-se a sede da pretendida biblioteca. $\mathrm{O}$ resultado do trabalho dos consultores foi apresentado em setembro de 1965, na XVI Reunião do Conselho Diretivo da OPAS, quando se definiu que a sede da Biblioteca seria estabelecida no Brasil, mais especificamente na cidade de São Paulo.

Além da preocupação em conhecer a produção latino-americana estava envolvida nesse processo a atenção diante da falta de livrostextos para o aprendizado e o ensino de medicina, projeto também incentivado pela OPAS:

la XVII Conferencia Sanitaria Panamericana ... Declara que dentro de las complejas dificultades que ofrece la educación médica en todos los países se ha advertido que la falta de libros de textos constituye uno de los obstáculos más graves para el ordenado desarrollo académico. (Documento n. 84, 1965, p. 127)

Uma segunda questão era a de que, dentro da sua política de investigação científica, havia a intenção de incentivar a permanência dos pesquisadores latino-americanos nos seus países de origem, intenção também confirmada no mesmo encontro:

Consciente de la necesidad de moderar la salida de América Latina de personal científico calificado, puesta de manifiesto por un estudio sobre la migración de personal de salud, hombres de ciencia e ingenieros de esa Región, la XVII Conferencia Sanitaria Panamericana pidió al Director que estudiara los medios de aumento y ampliación de los centros multinacionales para el adiestramiento e investigación en ciencias biológicas y en medicina en las Américas ... (Ibidem, p. 130)

Nessa conjuntura, a idéia da criação da Bireme já expunha a questão da localização física de sua sede atrelada a duas questões 
principais: a escola médica, principal beneficiária de uma tal instituição deveria ao mesmo tempo ser inovadora quanto às exigências do mercado de trabalho e integrar no mesmo espaço ensino, pesquisa e assistência. Essa dualidade, apontada como característica do ensino médico em geral por Juan Garcia (1972), caracterizou a organização da escola médica latino-americana em dois níveis, o técnico e o administrativo. Relacionavam-se então no encontro entre Estado, agência financiadora e escola médica três processos consecutivos no apoio ao ensino: a produção de conhecimento científico, a reprodução de pessoal e a de serviços de saúde.

\section{Brasil, São Paulo, Escola Paulista de Medicina}

A escolha do Brasil como sede da nova biblioteca pode ser avaliada inicialmente sob dois aspectos. Primeiramente, sob a perspectiva do crescimento do ensino de medicina no país e da comparação deste com o conjunto dos países da América Latina. Articula-se a isso o salto quantitativo particularmente agudo no número de escolas médicas na década de 1960 e o grande peso relativo do Brasil no total latino-americano, chegando o país a abrigar 44 por cento das escolas contabilizadas, como fica demonstrado no Gráfico 1:

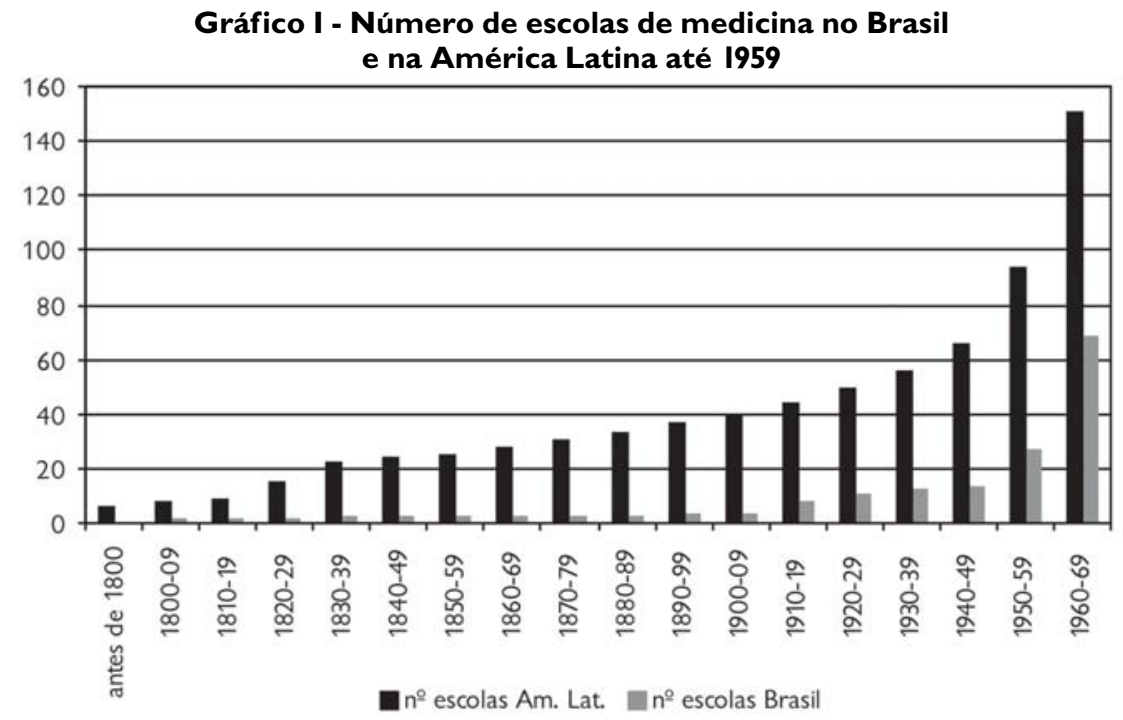

Fonte: Apud Garcia, 1972, p. 271.

Em segundo lugar, pode-se também destacar sumariamente a participação brasileira nas reuniões citadas para a consecução dos projetos de criação e instalação da Fepafem e da Biblioteca Regional. O Brasil aliou-se à National Library of Medicine, dos Estados Unidos, nos projetos de atenção à saúde que vinham sendo realizados em conjunto com a OPAS. 
Examinando-se os debates internos do Comitê Executivo da OPAS durante os anos de 1964 a 1967, é possível verificar que havia uma forte participação do Brasil naquele fórum. Na própria reunião de 1964 o representante escolhido para realizar o discurso de abertura e representar os delegados dos países presentes foi o brasileiro Manoel José Ferreira, suplente do Ministro da Saúde à época, Raymundo de Britto, também presente à reunião. Em sua fala, o delegado reafirmava a proposta de tratar a saúde como móvel do desenvolvimento sócio-econômico e de propor uma "nova responsabilidade" aos países latino-americanos. Em suas próprias palavras, executar uma "vigilancia permanente de los métodos técnicos y administrativos de trabajo, a la par que un continuo conocimiento de la evolución de la ciencia de la salud" (Documento n. 60, 1965, p. 16).

Por meio de um anexo final, é possível verificar que o Brasil participava ativamente de programas e auxílios propostos pela OPAS, ou como destinatário de bolsas e auxílios para pesquisadores, ou como local de intercâmbio. Em 1961 e 1962, um total de 107 professores de escolas de medicina e odontologia e funcionários de ministério de outros 14 países haviam realizado curso de seis semanas de duração na Faculdade de Higiene e Saúde Pública da Universidade de São Paulo. A Terceira Conferência de Diretores de Escolas de Saúde Pública da América Latina também foi realizada em São Paulo, em setembro de 1963. O Primeiro Seminário Viajante sobre Organização e Administração de Escolas de Medicina da América Latina, realizado em 1962, também esteve no Brasil, além de Argentina e Chile. Essa reunião tinha como objetivo colocar em contato escolas de medicina que realizavam planos de desenvolvimento reconhecidos (Ibidem, p. 328). O país foi também sede de cursos especializados: curso de malariologia, programa de administração de sistemas de abastecimento de água, e seminário internacional de controle da lepra, em 1958, contando com 42 participantes de dezesseis países.

Entre as faculdades que recebiam apoio ao ensino médico estava a Escola Paulista de Medicina, uma das mais beneficiadas em 1964, segundo relatório daquele ano. A EPM recebia auxílio de organismos paralelos de apoio, como se pode ver na Tabela 1.

No cômputo geral o Brasil recebeu um total de verbas no valor de 830.655 dólares, abaixo apenas da Colômbia, com 2.781 .830 dólares. Em terceiro lugar ficou o Paraguai, com 440 mil dólares.

Além de contarem com todas essas convergências, as atividades da EPM correspondiam àqueles quesitos apontados anteriormente, em que se aliava a produção de conhecimento científico de ponta com a formação de pessoal de saúde e a expansão de serviços. Tais atividades eram capitaneadas pelo trabalho que a instituição empreendia ao acoplar num mesmo espaço o ensino e o atendimento hospitalar. 
Tabela I - Apoio ao ensino de medicina

\begin{tabular}{|c|c|c|}
\hline Subvenção & $\begin{array}{l}\text { Valor total } \\
\text { (dólares) }\end{array}$ & Instituição \\
\hline \multirow[t]{6}{*}{ Fundação Rockefeller } & 2.000 .000 & $\begin{array}{l}\text { Faculdade de Medicina, } \\
\text { Universidade del Valle, Colômbia }\end{array}$ \\
\hline & 716.655 & $\begin{array}{l}\text { Escola Paulista de Medicina, } \\
\text { São Paulo, Brasil }\end{array}$ \\
\hline & 288.000 & $\begin{array}{l}\text { Universidade das Índias Ocidentais, } \\
\text { Jamaica }\end{array}$ \\
\hline & 240.200 & $\begin{array}{l}\text { Universidade Autônoma de } \\
\text { Guadalajara, México }\end{array}$ \\
\hline & 200.000 & $\begin{array}{l}\text { Faculdade de Medicina "Cayetano } \\
\text { Herendia”, Lima, Peru }\end{array}$ \\
\hline & 100.000 & $\begin{array}{l}\text { Universidade Nacional de Cuyo, } \\
\text { Argentina }\end{array}$ \\
\hline \multirow[t]{2}{*}{$\begin{array}{l}\text { Agencia para el } \\
\text { Desarrollo Internacional } \\
\text { (EUA) }\end{array}$} & 440.000 & $\begin{array}{l}\text { Escola de Medicina da Universidade } \\
\text { do Estado de Nova York, Buffallo, e } \\
\text { Faculdade de Medicina da } \\
\text { Universidade Nacional de } \\
\text { Asunción, Paraguai }\end{array}$ \\
\hline & 129.116 & $\begin{array}{l}\text { Escola de medicina da Universidade } \\
\text { de Tulane e outras na Colômbia; } \\
\text { Escola de Medicina da Universidade } \\
\text { do Estado de Luisiana e Faculdade } \\
\text { de Medicina da Universidade de } \\
\text { Costa Rica }\end{array}$ \\
\hline \multirow[t]{2}{*}{$\begin{array}{l}\text { Fundação } \\
\text { W. K. Kellogg }\end{array}$} & 334.000 & $\begin{array}{l}\text { Universidade de Antioquia, } \\
\text { Medellin, Colômbia }\end{array}$ \\
\hline & 114.000 & $\begin{array}{l}\text { Faculdade de Medicina, } \\
\text { Universidade de Recife, Brasil }\end{array}$ \\
\hline
\end{tabular}

Fonte: XV Reunion Consejo Directivo de la OPS e XVI Reunion Comité Regional de la OMS para las Américas, Documento Oficial n. 60, anexo 10, p. 332.

Todos esses fatores, certamente, foram levados em consideração pela comissão da OPAS responsável por definir o local de instalação da nova biblioteca regional. Houve, também, importantes articulações empreendidas por esforços de professores da própria EPM, especialmente Magid Iunes, do Departamento de Medicina Preventiva, e Antônio de Mattos Paiva, de Biofísica, este último ainda membro do primeiro Comitê Assessor Científico da Bireme, instalado em 1969.

A EPM, fundada como instituição privada em 1933, havia sido transformada em instituição pública federal recentemente, em fins de 1956 (Silva, 2003; 2001). Nesse mesmo momento, uma nova leva de profissionais, da América Latina em geral e do Brasil em 
particular, passou a aperfeiçoar seus estudos em universidades norte-americanas (Marinho, 2001). Magid Iunes era um representante dessa nova geração, e nessa condição esteve fortemente relacionado à NLM, mantendo vínculos pessoais com seu diretor, Martin M. Cummings.

Depois de definido o Brasil como país sede, a Comissão Especial da OPAS veio ao país, tendo visitado várias instituições e grupos de pesquisa. Segundo depoimentos, a decisão pela Escola Paulista não se deu sem muita discussão e articulação política (Paiva, 2002; Neghme, 2002; Población, 2002; Ferreira, 2004).

A escolha da Escola Paulista de Medicina para acolher a Bireme, portanto, pode ser entendida como uma conjunção de fatores imediatos, como o lobby levado a cabo por Magid Iunes junto às esferas diretivas da OPAS; a nova estrutura da Escola, por ser uma instituição de ensino ligada diretamente às instâncias decisórias do governo federal, naquele momento sob regime militar; e, não menos importante, as boas condições estruturais, com as instalações recém-construídas da sua biblioteca geral com verbas da Fundação Rockefeller e do Ministério da Educação, entendidas como as mais adequadas para abrigar a Bireme. Ainda sobre este último aspecto, cabe destacar que o acervo da instituição era ainda bastante modesto à época, mas contava com amplo espaço físico, condizente com as intenções do novo projeto.

Um fator técnico com interesse para os membros da Comissão, fortemente influenciada pela National Library of Medicine, ${ }^{2}$ foi o fato de que no Brasil apenas a Escola Paulista de Medicina, além das bibliotecas da Faculdade de Medicina da Universidade de Minas Gerais e da Universidade do Ceará, utilizava o mesmo sistema de catalogação da $\mathrm{NLM}^{3}$ o que facilitaria o trabalho posterior de colaboração com a biblioteca norte-americana.

\section{Instalação e primeiros tempos}

O nome Biblioteca Regional de Medicina (Bireme) inspirava-se no da instituição modelo, National Library of Medicine, e reafirmava a ambição da instituição em tornar-se um centro de referência para toda a América Latina.

O convênio entre o governo do Brasil, a Escola Paulista de Medicina e a OPAS seria, desde sua criação, renovado aproximadamente a cada cinco anos. No primeiro, em 1967, ficavam definidos os objetivos, as funções, a organização administrativa e as obrigações dos signatários, no intuito de dar suporte ao projeto.

Entre esses objetivos e funções estavam aqueles ligados à estruturação técnica institucional do novo órgão, com o acesso à base de dados MEDLARS, criada e sediada na NLM, acesso à coleção de periódicos da mesma bibliotecas e, sobretudo, com a 
missão de desenvolver a integração entre as bibliotecas cooperantes da América Latina. Além disso, internamente houve um grande esforço em ampliar a coleção de revistas na sede brasileira (Bireme/ OPAS, Boletim, 1969).

Do ponto de vista organizacional, o convênio estabelecia que a biblioteca seria administrada pela OPAS, "funcionando em estreita colaboração com a Escola Paulista de Medicina" (Ibidem), cabendo à primeira a nomeação do diretor da entidade. Decidiu-se também pela criação de um Comitê Técnico Assessor, que reuniria participantes de todas as instâncias decisórias na constituição da agência. Seria composto por representantes da OPAS, da NLM e da Fepafem, além de bibliotecários e cientistas da área da saúde para servir de apoio às ações da Bireme. Esse Comitê reuniu-se pela primeira vez em setembro de $1968 .^{4}$

Quanto às obrigações dos participantes, o convênio definia que cada um dos signatários se comprometeria com dotações anuais entre cinqüenta mil (MEC) e setenta e cinco mil dólares (OPAS) - e com responsabilidades específicas, tais como cessão, expansão e manutenção de espaço físico (EPM); fornecimento de bolsas de estudo e treinamento (MEC); e manutenção e expansão do acervo (OPAS).

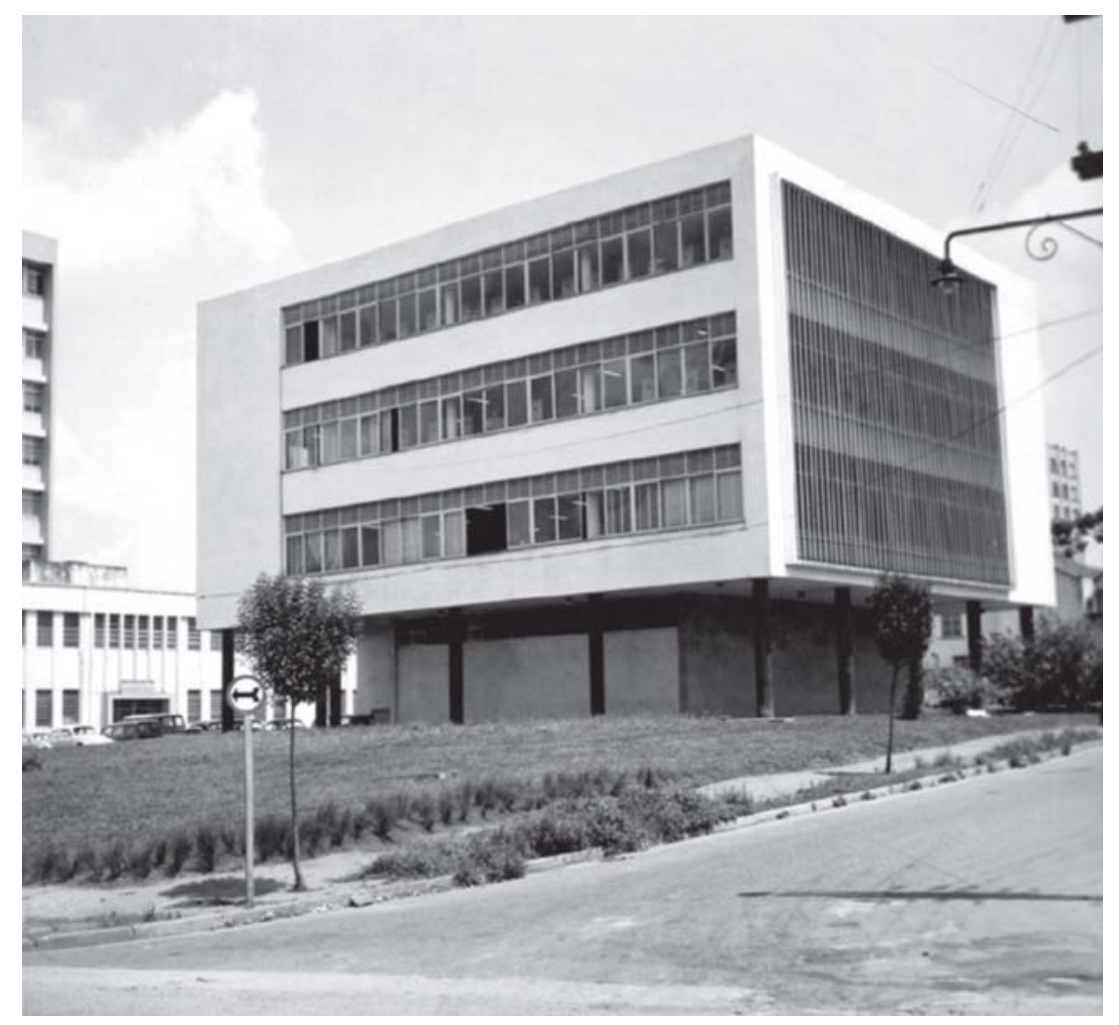

Figura 1 - Prédio da Bireme, em São Paulo. 
Os Gráficos 2 e 3 demonstram os valores alocados por cada um dos signatários para a instalação da Bireme no início de suas atividades.

Gráfico 2

Financiamento da instalação da BIREME (1967-1970), em US\$

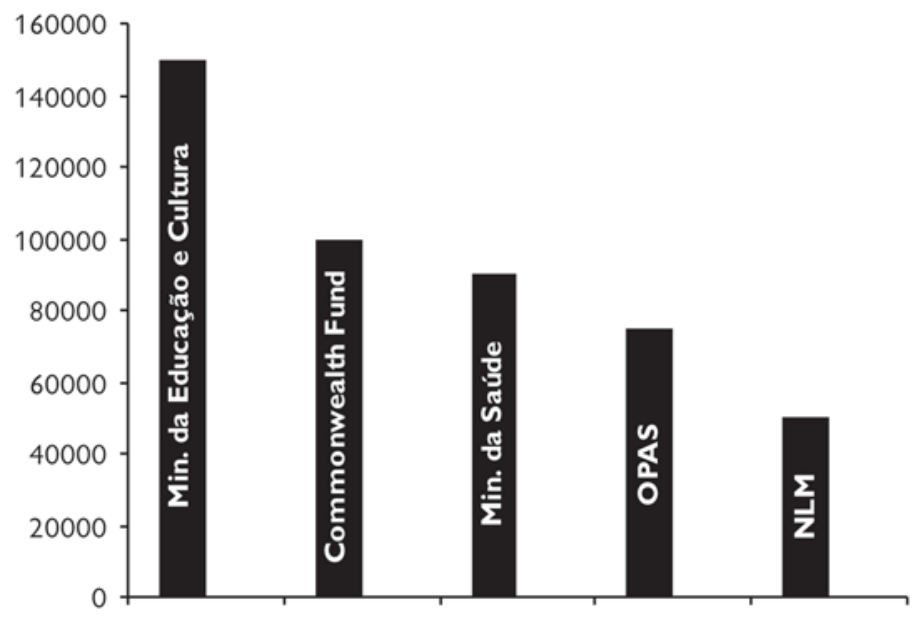

Fonte: Neghme e Newburn, 1970, p. 6.

Gráfico 3

Financiamento da instalação da BIREME (1967-1970), em \%

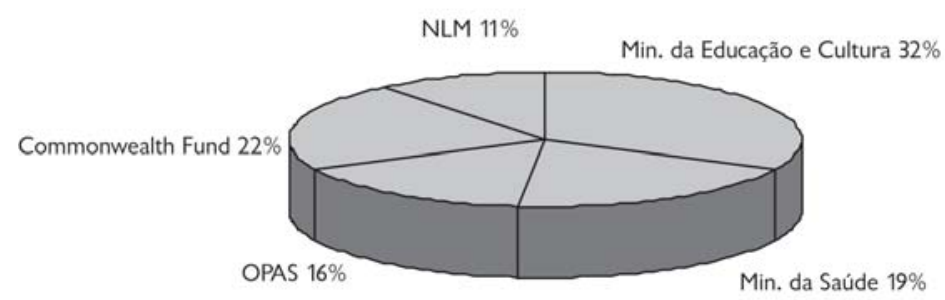

Fonte: Neghme e Newburn, 1970, p. 6.

A idéia de transferência de conhecimento e de capacitação de pessoal fora exposta desde o início, o que se converteu no oferecimento de cursos para agentes bibliotecários, que foram freqüentados por representantes de diversas bibliotecas latino-americanas. Esses cursos resultaram na organização de algumas publicações direcionadas a propor sistemas unificados de gerenciamento e organização de bibliotecas de saúde. ${ }^{5}$

Outro ponto definido como uma das prioridades da biblioteca consistiu na criação de catálogos coletivos dos principais periódicos científicos de saúde do período. Para isso buscava-se o apoio de catálogos anteriormente efetivados por outras instituições, tanto nacionais quanto estrangeiras, tais como o do Instituto Brasileiro 
de Bibliografia e Documentação, o Index Medicus e o Current Catalog, estes dois últimos constituindo-se nas principais referências mundiais para a área da saúde.

Além das publicações direcionadas à área médica havia também catálogos especializados, como o Tropical Diseases Bulletin, o Index to Dental Literature e o Index to Nursing Literature, publicações que serviriam para 'atualizar' o conhecimento dos profissionais da área. Em 1971, a coleção de revistas contava com 4.100 títulos, aproximadamente 2.184 dos quais comprados especialmente para compor o novo acervo e outros 1.425 adquiridos por subscrição ou intercâmbio com outras bibliotecas (Bireme, 1971).

Toda essa produção revela que as relações estabelecidas entre as agências cooperantes e seus participantes estavam assentadas sob bases atentas às mudanças no saber médico. A circulação de periódicos destaca a hegemonia de determinado modelos etiológico de conceber a doença e a concentração da investigação científica em instituições estatais distribuídas pelo mundo que podiam colocar seus dados e resultados nas principais revistas, facilmente localizadas nas principais bibliotecas.

A Bireme começou suas atividades de atendimento ao público em fevereiro de 1969 (Bireme/OPAS, Boletim, 1969), sob a coordenação técnica do bibliotecário da NLM, Robert Newburn. ${ }^{6}$ Pouco tempo depois seria nomeado como primeiro diretor científico o médico Amador Neghme, naquele momento membro do Conselho Diretivo da OPAS.

A definição de Negme como diretor forneceu grande impulso para o reconhecimento da biblioteca no âmbito acadêmico, principalmente nos países da América do Sul. Ele havia sido o primeiro presidente da Fepafem e decano da Faculdade de Medicina da Universidade do Chile, além de homem de ciências e parasitólogo reconhecido.

As compilações bibliográficas oferecidas pela Bireme se concentravam em temas de ensino de especialidades, principalmente sobre educação médica continuada e informes sobre novas metodologias como recursos para o ensino médico. Em 1973, o atendimento ao público proporcionou a produção de 972 bibliografias gerais e cerca de 25 outras específicas, sobre educação médica. ${ }^{7}$ Um terço dessas consultas atendeu a solicitações de países da América Latina (Bireme/OPS, Boletim, 1973). Porém, apenas 10 por cento dessas consultas resultaram em empréstimos externos, sendo 90,4 por cento destas para o Brasil e 9,6 por cento para outros países. Instalavamse ainda atividades como o serviço de permuta e doações, por exemplo, que visava atualizar os acervos das bibliotecas participantes, atendendo em 63 por cento das vezes a bibliotecas brasileiras e, em 37 por cento, às de outros países da América do Sul.

Diferentes entidades passaram a estabelecer relações formais com a Bireme e a assinar acordos de cooperação. As instituições nacio- 
nais que inauguraram tais cooperações foram a Faculdade de Odontologia e a Escola de Medicina Veterinária, ambas da Universidade de São Paulo. Entre as instituições latino-americanas que iniciaram acordos similares estavam o Instituto de Nutrição da América Central e do Panamá (Incap), da Guatemala, o Centro LatinoAmericano de Perinatologia e Desenvolvimento Humano, do Uruguai, e o Centro Pan-Americano de Engenharia Sanitária e Ciências Ambientais, do Peru.

Esses acordos estavam relacionados aos pressupostos iniciais da organização da biblioteca: incrementar as relações entre instituições de ensino e saúde latino-americanas, tendo como área de concentração temas relacionados com a saúde pública e o ensino médico. Assim, a instalação da Bireme pode ser vista como parte ativa do projeto da OPAS voltado a fornecer meios de consolidar o conhecimento sobre a saúde em instituições sediadas na América Latina, que ao mesmo tempo passou a abrir espaços para o intercâmbio cada vez maior entre os profissionais da área em diferentes países.

Logo em 1971, portanto com menos de quatro anos de existência, a Bireme passou por ampliações físicas subvencionadas pela EPM. Recebeu nessa época auxílio para a implantação de Programas de Educação da Fundação W. K. Kellogg, no montante de cinqüenta mil dólares, além de auxílio do governo do Brasil para o estabelecimento de subcentros regionais em outras capitais brasileiras, no valor de sessenta mil dólares. Obteve recursos também da Fundação de Amparo à Pesquisa do Estado de São Paulo Fapesp, dez mil dólares, e da Municipalidade de São Paulo, dois mil dólares, e uma verba suplementar da OPAS naquele ano de $59 \mathrm{mil}$ dólares. No total, os fundos disponíveis, destinados à Bireme em 1971, giraram em torno de 270 mil dólares.

Mantidos os auxílios das instituições apontadas, os valores definidos para a Bireme nos anos de 1972 e 1973 cresceram, assegurados respectivamente em 307 mil dólares e 312 mil dólares (Convênios). Tais auxílios revelam a aceitação e a amplitude que adquiriam os serviços da biblioteca. O pronto estabelecimento de um projeto tão amplo possibilitou propostas de ampliação dos serviços e a geração de novos acordos com bibliotecas de países até então não participantes.

A movimentação dos governos latino-americanos em torno do tema da saúde como fator de integração regional refletia atividades paralelas. Na mesma época a Terceira Reunião Especial de Ministros de Saúde das Américas (2 a 9 de outubro de 1972), ${ }^{8}$ quando se aprovou o Plano Decenal de Saúde para as Américas, projeto que previa ações de saúde para o restante daquela década. O evento produziu diretrizes específicas para as Bibliotecas Regionais. Reiteravase a importância das atividades da Bireme para a América Latina e 
recomendava-se a criação de sistemas nacionais de documentação em ciências da saúde nos diversos países representados no evento (Bireme/OPAS, Boletim, 1973).

Em 1972, a Bireme entrou definitivamente no mundo da informação eletrônica com a instalação de um terminal Olivetti, operando através do Satélite Intersalt com a NLM pelo sistema MEDLINE (antigo MEDLAR). ${ }^{9}$ Esse sistema atuava com um acervo de 2.300 revistas, localizadas em 180 bibliotecas médicas operando nos Estados Unidos, nove no Canadá e na Inglaterra e uma na França. O Fundo de Desenvolvimento das Nações Unidas apoiou o projeto, financiando a compra dos equipamentos, quando foi assinado um acordo entre a Bireme, o Instituto de Energia Atômica, a OPAS e a NLM. Em abril de 1974, o sistema começou a funcionar em procedimento on-line, ou seja, com um banco de dados do sistema MEDLINE conectado a um computador IBM, com terminais adquiridos pelo PNUD (Programa das Nações Unidas para o Desenvolvimento). Os sistemas passaram a ser recebidos em Brasília, Rio de Janeiro e Recife em agosto de 1975, também com o auxílio de computador IBM do Instituto de Estudos Avançados, da USP.

Iniciava-se, assim, um novo período na história da instituição, em que se coordenavam novos processos de transmissão de dados com a ampliação dos serviços e atividades da biblioteca, no que é hoje o ponto focal das atividades da Bireme.

O primeiro diretor, Amador Neghme, ficou no cargo entre 1969 e fevereiro de 1976, um ano depois da saída de Abraham Horwitz da direção da OPAS, encerrando assim o período de instalação e organização das atividades da Bireme. A Biblioteca permaneceu intimamente conectada com a própria história da OPAS e da saúde, como mobilizadora de políticas de desenvolvimento local e regional e de integração na América Latina. Nesse mesmo período é que, no Brasil, passam a ser discutidas e implementadas mudanças na idéia de universidade e de ensino, com a Reforma Universitária: alteram-se as graduações e se instituem as pós-graduações em diferentes áreas.

\section{Conclusão}

Tradicionalmente, os estudos históricos latino-americanos abordam as questões de saúde e higiene públicas como um campo de organização quase que exclusivo da medicina, em obediência às políticas públicas de saúde de cada país. Porém, é importante verificar que é necessário ainda um novo olhar para uma ampla gama de temas que podem compor esse universo. A cooperação internacional na área médica permite incorporar, após a Segunda Guerra Mundial, um número cada vez maior de problemas e de possibilidades interpretativas. Inserido num contexto de profundas trans- 
formações no campo das ciências, da educação e da informação, e também da saúde pública, o estudo da criação da Bireme pretende se apresentar como um exemplo desse processo.

Em nosso estudo tem sido possível verificar que aspectos políticos se entrelaçaram com projetos científicos e educacionais, esboçando uma complexa rede de interesses. A Bireme aparece, pois, como um fenômeno histórico de peculiar importância, não apenas para a história das ciências da informação e da saúde na América Latina, mas também para a história dos projetos de integração da região, incluindo-se a própria Organização Panamericana de Saúde.

Hoje a Bireme atende a um contingente cada vez maior de interessados na literatura científica em várias áreas. Em 1982, passou a ser denominada Centro Latino-Americano e do Caribe de Informação em Ciências da Saúde, mas sua sigla persistiu. Sua função é descentralizar e desenvolver produtos e serviços, elaborar metodologias de acesso à informação em bases descentralizadas, além de indexar e ampliar o próprio acesso a bases de dados e à literatura científica nas diversas sedes que compõem o sistema. A tecnologia da informática, com o uso da base de dados LILACS e dos diversos $c d$ roms desenvolvidos, tem permitido uma ampliação bastante grande do trabalho realizado. Mais recentemente, a criação da BVS, Biblioteca Virtual em Saúde, em diferentes sub-áreas, demonstra o processo de expansão das questões referentes a informação como um campo inquestionável da atenção à saúde e da atividade científica em geral. ${ }^{10}$ Tal visão resume o enfoque deste trabalho, que pretendeu apresentar, sucintamente, a formação de uma rede de circulação de conhecimento médico. A tentativa de conectar diferentes fatores (científicos, sócio-políticos, econômicos e estruturais) para explicar a criação de uma instituição como a Bireme aponta nossa vontade de contribuir para o entendimento da saúde como um processo amplo. Foi possível detectar, num período específico da história, a consolidação simultânea de políticas específicas de educação, de informação e de desenvolvimento, para o Brasil e, mais amplamente, para a América Latina.

\section{NOTAS}

*A expressão 'biblioteca sem paredes' é utilizada na bibliografia para designar catálogos, coletâneas e coleções, instrumentos criados como "paliativo à impossibilidade da universalidade" de seus conteúdos (Chartier, 1999, p. 117). Este artigo apresenta resultados parciais do projeto de pesquisa "História da Bireme", desenvolvido pela equipe de pesquisa do Centro de História e Filosofia das Ciências da Saúde (CeHFi) da Universidade Federal de São Paulo (Unifesp) e financiado pelo Centro Latino-Americano e do Caribe de Informação em Ciências da Saúde (Bireme/OPAS), sob a direção de Abel Laerte Parker, mestre em Ciências da Informação pela School of Information Studies da Syracuse University, USA.

${ }^{1}$ A primeira sede da Associação foi no Rio de Janeiro, quando a direção executiva estava a cargo do médico Dr. Ernani Braga e a direção geral cabia ao Dr. Amador Neghme (Boletim, 1969). 
2 A National Library of Medicine dos Estados Unidos foi a primeira no campo biomédico a aplicar o ordenamento eletrônico de publicações científicas, criando em 1963 o sistema MEDLARS - Medical Literature Analysis Retrieval System (Boletim, 1970).

3 O acervo da Biblioteca Central da EPM naquele momento contava com 1.831 títulos de livros e 1.992 títulos de periódicos, enquanto a Biblioteca da FMUSP contava com 69.896 volumes ao todo. Cf. IBBD, Bibliografia..., 1960 e IBBD, Bibliotecas..., 1962, p. 198-9.

4 Participaram dessa primeira reunião o diretor da NLM, Martin M. Cummings, como presidente do Comitê; o chefe da Biblioteca de Medicina de Boston, Harold Bloomquist; o diretor do Centro de Informação da Syntex International do México, Dr. Armando Sandoval, como relator; o diretor adjunto da Fepafam, Dr. Mário Chaves; o diretor do Instituto de Investigações Bioquímicas de Buenos Aires, Dr. Luis F. Leloir; o chefe do Departamento de Biofísica e Fisiologia da EPM, Dr. Antonio de Mattos Paiva; e o Chefe do Departamento de Desenvolvimento e Coordenação Científica da OPAS, Dr. Maurício Martins da Silva, como secretário. Além destes, foram também incorporados, como consultores temporários, o professor Dr. Jan Koch-Weser, da Universidade de Harvard, e o gerente do Serviço de Informação da Miehle-Goss-Dexter de Chicago, Carlos Cuitino (Boletim, 1970).

5 As duas primeiras publicações desse tipo foram os Requisitos mínimos para organização e funcionamento da biblioteca de uma escola de medicina e as Sugestões para a organização da biblioteca de uma escola de medicina, ambos de 1970 .

${ }^{6}$ R. Newburn afastou-se no início do funcionamento da Bireme, em 21 de janeiro de 1970, tendo sido substituído interinamente por Washington José Mouta, professor da Faculdade de Biblioteconomia da Universidade de Brasília, que já exercia o cargo de chefe dos serviços técnicos da Bireme.

7 Para se ter uma idéia dos números atuais relacionados com os serviços oferecidos pela Bireme, no ano de 2001 foram consultados localmente 404.499 fascículos de revistas e processadas 355.751 fotocópias de artigos e documentos. Destas consultas, 177.315 (64\%) relacionavam-se a coleções locais, 79.237 (28,6\%) a bibliotecas cooperantes, 20.501 (7,4\%) aos serviços de comutação bibliográfica internacional, British Library e NLM (Bireme. Processo de Avaliação anual para renovação de assinaturas, 2003).

8 O vice-presidente da Conferência de Saúde de 1972, que aprovou o Plano decenal para a saúde, era um representante do Brasil.

9 Pertencente à National Library of Medicine, em Bethesda, dos Estados Unidos, e adotado desde 1964. Ver Boletim Informativo, v. V, mar.-maio 1973, n. 2.

10 Para conhecer melhor as atividades atuais da Bireme, consultar sua página, no endereço www.bireme.br/bvs/ bireme/homepage.htm.

\section{REFERÊNCIAS BIBLIOGRÁFICAS}

Chartier, Roger 1999

Cueto, Marcos $1997 a$

Cueto, Marcos 1997b

Cueto, Marcos 1996

A explosão educativa 1979

Finkelman, Jacobo (org.) 2002

Fleury, Sonia Maria 1997
A aventura do livro: do leitor ao navegador.

São Paulo: Unesp/Imprensa Oficial do Estado.

El regreso de las epidemias. Salud y sociedad en el Perú del siglo XX. Lima: IEP.

Science under adversity: Latin American medical research and American private philanthropy, 1920-1960. Minerva, n. 35, p. 233-45.

Los ciclos de la erradicación: la Fundación Rockefeller y la Salud Pública Latinoamericana, 1918-1940. In: Cueto, Marcos. (org.) Salud, cultura y sociedad en América Latina: nuevas perspectivas históricas. Lima: IEP/OPS. p. 179-201.

Rio de Janeiro: Salvat.

Caminhos da saúde pública no Brasil.

Rio de Janeiro: Ed. Fiocruz.

Políticas sociais e cidadania na América Latina.

In: Canesqui, Ana Maria (org.) Ciências Sociais em Saúde.

São Paulo: Hucitec/Abrasco. 
Galison, Peter; Hevly, Bruce 1992

Garcia, Juan César 1972

Hobsbawm, Eric 1995

Lima, Nísia Trindade 2002

Marinho, Maria

Gabriela S. M. 2001

Nunes, Everardo

Duarte

1999-2000

Nunes, Everardo

Duarte

1989

OPS

1992

$\mathrm{PAHO} / \mathrm{WHO}$

2002

Sevcenko, Nicolau 2001

Silva, Márcia

Regina Barros 2003

Silva, Márcia Regina Barros 2001
Big Science. The growth of large-scale research. Los Angeles: Stanford University Press.

La educatión médica en la América Latina. Washington (DC): OPAS.

Era dos extremos: o breve século XX (1914-1991).

São Paulo: Companhia das Letras.

O Brasil e a Organização Pan-Americana da Saúde: uma história de três dimensões. In: Finkelman, Jacobo (org.) Caminhos da Saúde Pública no Brasil. Rio de Janeiro: Ed. Fiocruz. p. 23-116.

Norte-americanos no Brasil: uma história da Fundação Rockefeller.

Bragança Paulista (SP): Ed. Universitária São Francisco.

Ensinando ciências sociais em uma escola de medicina: a história de um curso (1965-1990). História, Ciências, Saúde - Manguinhos, v. VI, n. 3, p. 63157, nov. 1999-fev. 2000

Juan César Garcia: pensamento social em saúde na América Latina.

São Paulo: Cortez/Abrasco.

Pro Salute Novi Mundi: historia de la Organización Panamericana de la Salud. Washington (DC).

Celebrando 100 años de salud: en búsqueda de una América saludable. Washington (DC).

A corrida para o século XXI. No loop da montanha-russa.

São Paulo: Companhia das Letras.

Estratégias da ciência: a história da Escola Paulista de Medicina (1933-1956). Bragança Paulista (SP): Ed. Universitária São Francisco.

O ensino médico em São Paulo e a criação da Escola Paulista de Medicina. História, Ciências, Saúde - Manguinhos, v. VIII, n. 3, p. 541-66.

\section{FONTES CONSULTADAS}

Bireme

Bireme

Bireme

1967-1973

Bireme/OPAS

1970

Bireme/OPAS

1970

Bireme/OPAS

Bireme/OPAS

1969-1970
Processo de avaliação anual para renovação de assinaturas.

São Paulo.

Biblioteca Regional de Medicina de la Organización Panamericana de la Salud. São Paulo.

Convênio de criação da Biblioteca Regional de Medicina, 1.3.67 a 15.11.73.

Disponível em www.globalpolicy.org/globaliz/charts/techsp2.htm.

Sugestões para a organização da biblioteca de uma escola de medicina. São Paulo.

Requisitos mínimos para organização e funcionamento da biblioteca de uma escola de medicina. São Paulo.

Boletim Informativo - Bireme/OPAS, n. 1, vol. 5, jan./fev, 1973; n. 4, vol. 5, set./dez., 1973

Boletim Informativo - Bireme/OPAS, n. 1, vol.1, maio 1969, n. 4, dez. 1970. 


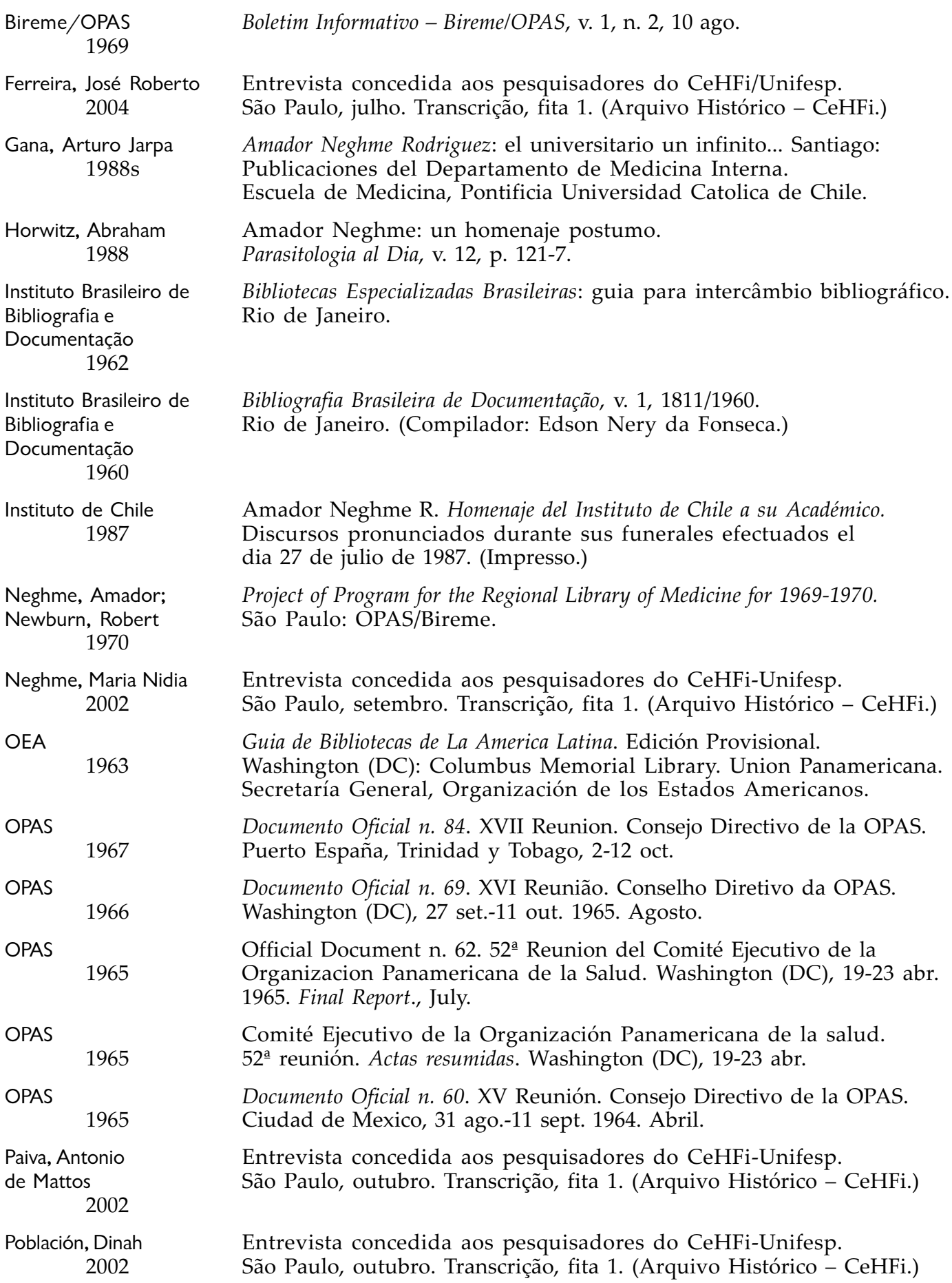

Boletim Informativo - Bireme/OPAS, v. 1, n. 2, 10 ago.

Entrevista concedida aos pesquisadores do CeHFi/Unifesp. São Paulo, julho. Transcrição, fita 1. (Arquivo Histórico - CeHFi.)

Amador Neghme Rodriguez: el universitario un infinito... Santiago: Publicaciones del Departamento de Medicina Interna. Escuela de Medicina, Pontificia Universidad Catolica de Chile.

Amador Neghme: un homenaje postumo. Parasitologia al Dia, v. 12, p. 121-7.

Bibliotecas Especializadas Brasileiras: guia para intercâmbio bibliográfico. Rio de Janeiro.

Bibliografia Brasileira de Documentação, v. 1, 1811/1960.

Rio de Janeiro. (Compilador: Edson Nery da Fonseca.)

Amador Neghme R. Homenaje del Instituto de Chile a su Académico. Discursos pronunciados durante sus funerales efectuados el dia 27 de julio de 1987. (Impresso.)

Project of Program for the Regional Library of Medicine for 1969-1970. São Paulo: OPAS/Bireme.

Entrevista concedida aos pesquisadores do CeHFi-Unifesp. São Paulo, setembro. Transcrição, fita 1. (Arquivo Histórico - CeHFi.)

Guia de Bibliotecas de La America Latina. Edición Provisional. Washington (DC): Columbus Memorial Library. Union Panamericana. Secretaría General, Organización de los Estados Americanos.

Documento Oficial n. 84. XVII Reunion. Consejo Directivo de la OPAS. Puerto España, Trinidad y Tobago, 2-12 oct.

Documento Oficial n. 69. XVI Reunião. Conselho Diretivo da OPAS. Washington (DC), 27 set.-11 out. 1965. Agosto.

Official Document n. 62. 52a Reunion del Comité Ejecutivo de la Organizacion Panamericana de la Salud. Washington (DC), 19-23 abr. 1965. Final Report., July.

Comité Ejecutivo de la Organización Panamericana de la salud. $52^{a}$ reunión. Actas resumidas. Washington (DC), 19-23 abr.

Documento Oficial n. 60. XV Reunión. Consejo Directivo de la OPAS. Ciudad de Mexico, 31 ago.-11 sept. 1964. Abril.

Entrevista concedida aos pesquisadores do CeHFi-Unifesp.

São Paulo, outubro. Transcrição, fita 1. (Arquivo Histórico - CeHFi.)

Entrevista concedida aos pesquisadores do CeHFi-Unifesp.

São Paulo, outubro. Transcrição, fita 1. (Arquivo Histórico - CeHFi.) 